Tytti Rajahonka ja Emilia Tuohimetsä

\title{
VAKA, VANHA, ASIAKKAILLEMME MUOTOILTU \\ - KOKEMUKSIA PALVELUMUOTOILUSTA SKS:N KIRJASTOSSA
}

Miten palvelumuotoilu ja asiakaslähtöisyys solahtavat tieteelliseen asiantuntijaorganisaatioon, jolla on 190-vuotiset perinteet?

SKS:n kirjastossa toteutettiin syksyllä 2019 palvelumuotoiluhanke, jossa suunniteltiin tilauudistus. Mitä opimme asiakaslähtöisyydestä, ja millaisia eväitä palvelumuotoilun lähestymistapa antoi kirjaston tilojen ja palvelujen kehittämiseen?

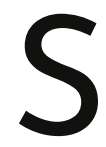
uomalaisen Kirjallisuuden Seuran (sks) kirjasto on tieteellinen erikoiskirjasto, jonka keskeisiä aloja ovat kulttuurien tutkimus ja kirjallisuudentutkimus. Kirjasto on kaikille avoin ja sijaitsee Helsingin Kruununhaassa. Asiakkaitamme ovat esimerkiksi tutkijat, opiskelijat ja keskeisalojemme harrastajat.

Palvelumuotoiluhankkeemme toteutettiin yhteistyössä palvelumuotoilutoimisto Kuudes Helsingin kanssa. Siinä suunniteltiin kirjaston sisääntulokerrokseen tilauudistus, joka valmistui alkuvuodesta 2020 . Tässä artikkelissa kerromme hankkeen etenemisestä erityisesti tilauudistukseen keskittyen. Haasteena oli, miten sovittaa nykypäivän kirjastokävijöiden tarpeet historialliseen, vuonna I 890 valmistuneeseen sKs:n päärakennukseen.

Artikkelimme pääpaino on kirjaston ja sKs:n muun henkilökunnan kokemuksissa ja siinä, millaisen vastaanoton palvelumuotoiluhanke sai työyhteisössämme.

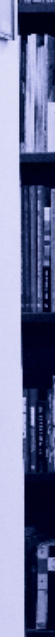

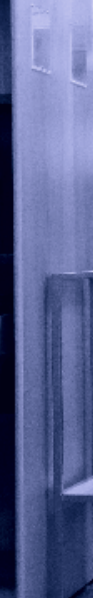

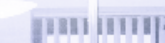

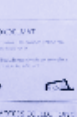

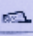

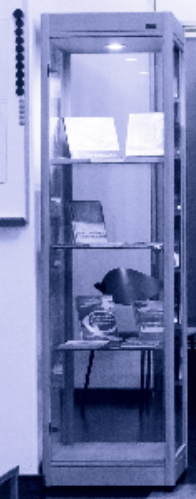

$\approx$ Uudistuksen myötä esimerkiksi uutuuskirjat pääsevät aiempaa paremmin esiin: asiakkaat näkevät ne heti

kirjastoon sisään astuttuaan. Kuva: Gary Wornell.

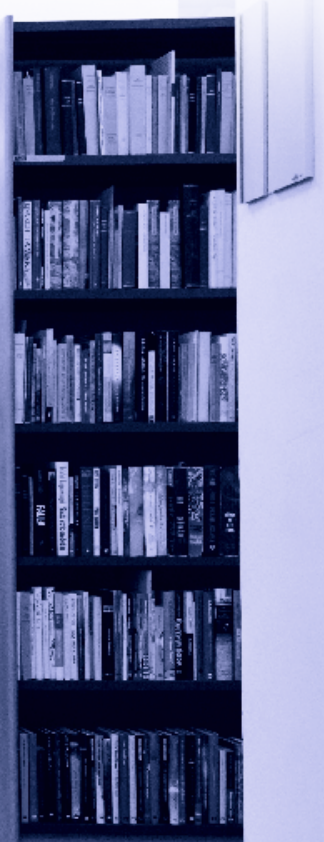




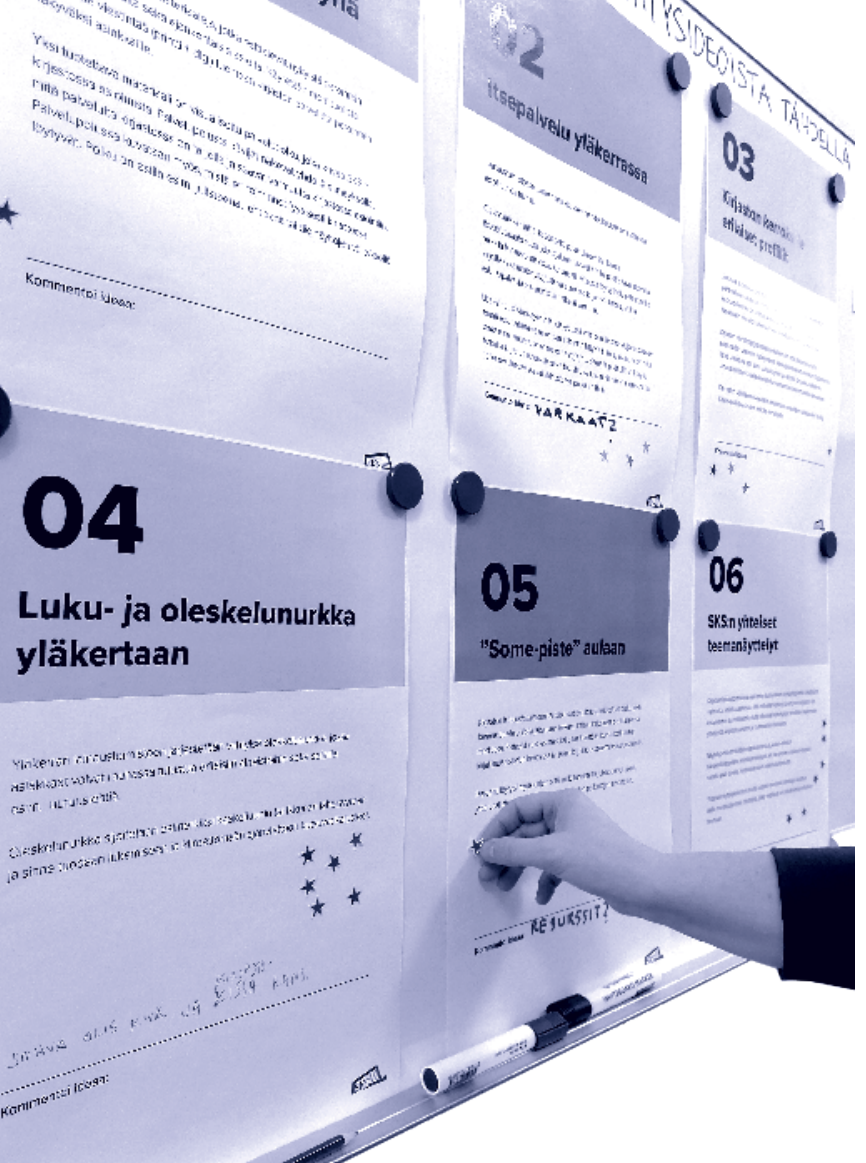

Tilasuunnittelu palvelumuotoilun keinoin: työpajoja, havainnointia ja asiakkaiden kuulemista

Mikä tekee tilauudistuksen suunnittelusta nimenomaan palvelumuotoilua? Yleisesti palvelumuotoilulla (engl. service design) tarkoitetaan palvelujen kehittämistä yhdessä niiden käyttäjien kanssa. Päämääränä on parantaa käyttäjän palvelukokemusta. (Palvelumuotoilun määritelmästä ks. esim. Mager 2008.)

Suomalaisissa kirjastoissa palvelumuotoilua on hyödynnetty erityisesti tilasuunnittelussa (ks. esim. Linnanketo 2015). Meidän tilauudistustarpeemme lähtökohtana oli itsepalvelumahdollisuuksien parantaminen kirjaston käyntikerroksessa.
«Palvelukonseptit asiakkaiden

äänestettävänä

Kuva: Tytti Rajahonka.

Hankkeemme aikana järjestettiin kaksi palvelumuotoilijoiden vetämää kehittämistyöpajaa. Ensimmäiseen työpajaan osallistui kirjaston asiakkaita sekä muutama sKs:n henkilökunnan edustaja. Työpajassa selvitettiin asiakkaiden kokemuksia kirjastossa asioinnista vaihe vaiheelta. Välineinä olivat $\mathrm{mm}$. palvelupolkujen laatiminen pienryhmissä sekä näiden polkujen kävely kirjastossa kirjaten osallistujien huomiot talteen.

Toisessa työpajassa työstimme kirjaston henkilökunnan kesken ratkaisuja asiakastyöpajassa kiteytyneisiin kehittämisideoihin. Näistä valittiin kuusi ratkaisuehdotusta jatkoon asiakasvalidointiin eli kirjaston kävijöiden äänestettäväksi. Nämä uudet palvelukonseptit huomioitiin Kuudes Helsingin laatimassa sisustussuunnitelmassa.

Hankkeen aikana palvelumuotoilijat myös havainnoivat ja haastattelivat kirjaston kävijöitä. Kirjaston asiakaspalvelijat puolestaan selvittivät asiakkaiden kulkureittejä sekä työpisteiden käyttöä. Kokosimme myös asiakastietoa eri lähteistä ja hahmottelimme asiakasprofiileja.

\section{Kysely kirjaston}

henkilökunnalle ja muiden osastojen kollegoille

Palvelumuotoiluhankkeen päättymisen jälkeen halusimme selvittää, miten hanke näyttäytyi kirjaston henkilökunnalle ja sks:n muille osastoille. sks:ssa on noin 80 työntekijää, joille tiedotimme hankkeesta esimerkiksi sKs:n 


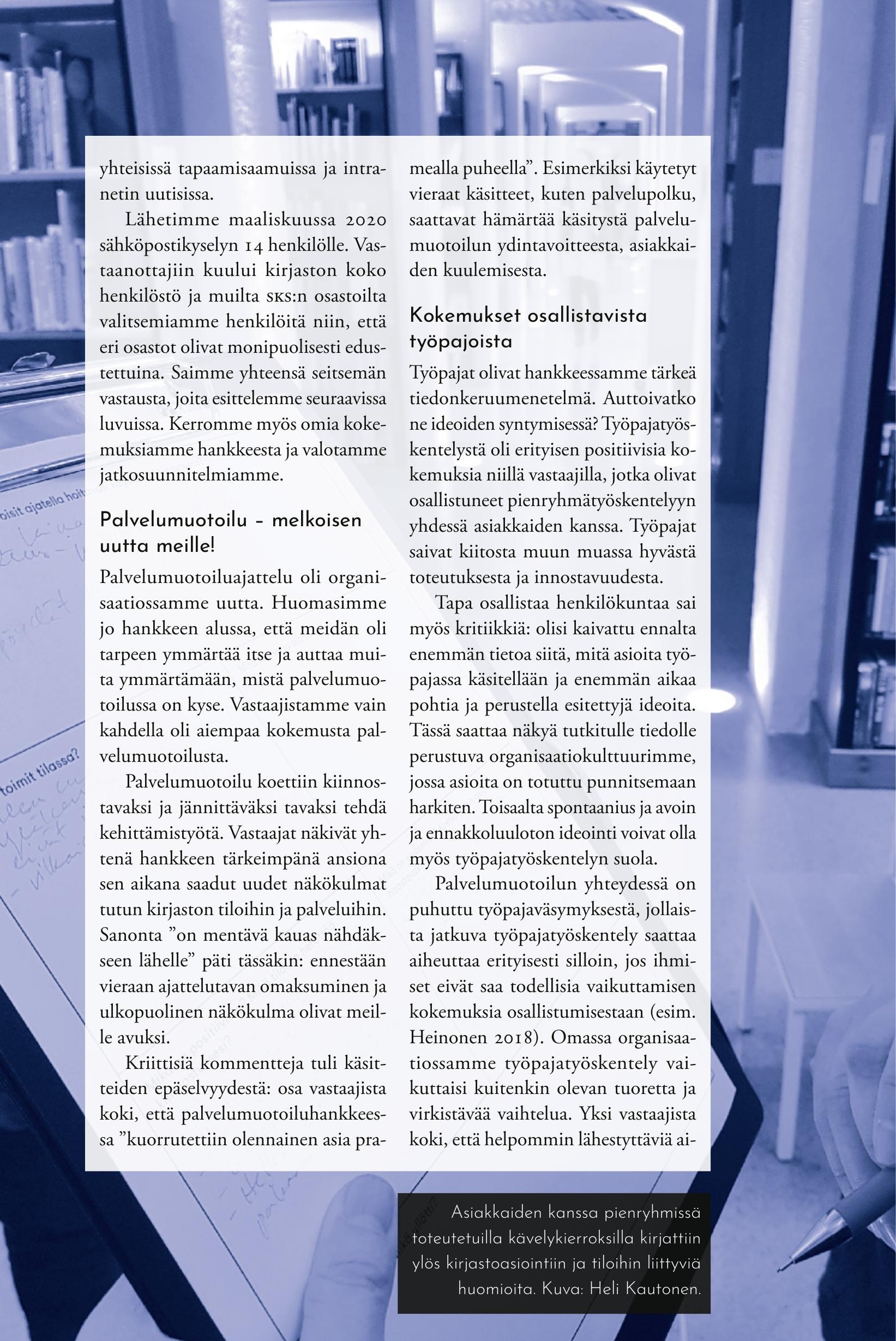


asiakaspalvelussa työskenteleviä. Toivomme kuitenkin palvelumuotoiluhankkeen vahvistaneen ajatusta siitä, että myös kulisseissa tapahtuva toimintamme, kuten hankinta sekä kuvailu ja muu metadatatyö, tehdään ensisijaisesti asiakasta varten. Tämä antaa suuntaa ja prioriteetteja toiminnallemme.

\section{Katse tiloja pidemmälle, asiakaskuuleminen osaksi arkea}

Saimme hankkeen aikana paljon ideoita palvelujemme kehittämiseksi ja vahvistusta jo aiemmin tunnistamillemme kehittämiskohteille. Otamme niitä toteutettaviksi vaiheittain. Kiinnitämme jatkossa huomiota mm. opasteisiin ja tilojen profilointiin asiakkaiden erilaisiin tarpeisiin. On tärkeää huomioida myös ne hankkeessa syntyneet kehit- tämisideat, jotka eivät liity tiloihin.

Oppimastamme palvelumuotoiluajattelusta on ollut hyötyä koronapandemian aiheuttaman poikkeustilanteen aikana, kun olemme joutuneet kehittämään nopeasti uusia asiakaspalvelun käytänteitä. Asiakkaidemme näkemyk-

kena.

Tavoitteenamme on, että palvelujen kehittäminen yhdessä asiakkaiden kanssa on meille jatkossa arkipäiväistä toimintaa. Opimme, että asiakaskuulemisen tapoja kannattaa hyödyntää omatoimisesti ja rohkeasti. Hankkeen jälkeen olemmekin jo toteuttaneet ovensuukyselyitä. Asiakkaiden osallistamisesta digitaalisten välineiden avulla on puolestaan tullut poikkeusaikana meille entistäkin ajankohtaisempi uusi kehittämiskohde.

\section{Lähteet}

SKS:n strategia 20 I 8-2022. https://www.finlit.fi/fi/sks/organisaatio/sksn-strategia-20 I 8-2022 (luettu 27. I I. 2020)

Heinonen, T., 2018. Kaikki muuttuu muotoiluksi - Suojaudu asianmukaisesti (Osa I). https://medium.com/@TaneliHeinonen/kaikki-muuttuu-muotoiluksi-suojauduasianmukaisesti-osa-I-addbco5e6422 (luettu 27. I I. 2020)

Linnanketo, H., 20 I 5 . Palvelumuotoilua suomalaisissa kirjastoissa - katsaus kolmeen tapaukseen. Opinnäytetyö (AMK). Turun ammattikorkeakoulu, kirjasto- ja tietopalvelun koulutusohjelma. http://urn.fi/URN:NBN:fi:amk-20 I 50603 I 2 I 80

Mager, B., 2008. Service design definition. Teoksessa Erlhoff, M. \& Marshall, T. (toim.): Design dictionary : perspectives on design terminology. s. 354-357. Birkhäuser. https://doi.org/I o. I007/978-3-7643-8 I 40-0

\section{Kirjoittajat}

TytTi Rajahonka

Suomalaisen Kirjallisuuden Seura tytti.rajahonka@finlit.fi
Emilia Tuohimetsä

Suomalaisen Kirjallisuuden Seura emilia.tuohimetsa@finlit.fi 